MASA TIV $\mathrm{k}=707 / 3$

\title{
VENUS CLOUD PROPERTIES: INFRARED OPACITY AND MASS MIXING RATIO
}

R. E. SAMUELSON

R. A. HANEL

L. W. HERATH

V. G. KUNDE

W. C. MAGUIRE

(NASA-TM-X-70713) VENUS CLOUD PROPERTIES:

INFRARED OPACITY AND HASS MIXING RATIO

N 74-30289

(NASA) 51 P HC $\$ 5.75$

CSCL O3E

Unclas

G3/30 54810

JUNE 1974 
VENUS CLOUD PROPERTIES:

INFRARED OPACITY AND MASS MIXING RATIO

\author{
R. E. Samuelson, R. A. Hanel, L. W. Herath,
}

V. G. Kunde and W. C. Maguire

June 1974

Laboratory for Planetary Atmospheres

Goddard Space Flight Center

Greenbelt, Maryland 


\section{CONTENTS}

$\underline{\text { Page }}$

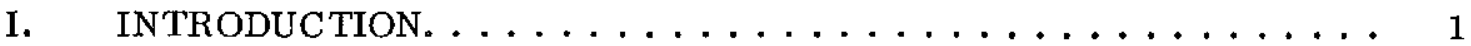

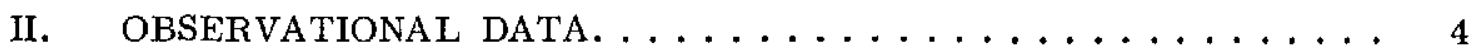

III. RADIATIVE TRANSFER MODEL ................. 9

IV. ATMOSPHERIC AND CLOUD OPACITY .............. 12

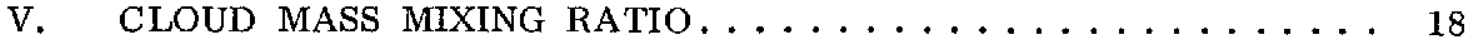

VI. SULFURIC ACID ...................... 23

VII. LUNAR EMISSIVITY AND MULTIPLE SCATTERING

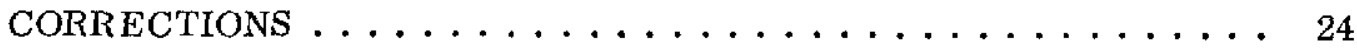

A. Lunar Emissivity . . . . . . . . . . . . . . 25

B. Multiple Scattering .................... 25

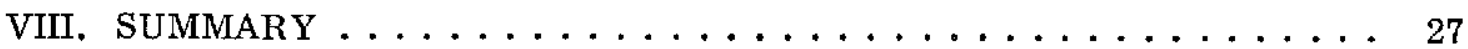

APPENDIX - The Volume Extinction Coefficient from the Mariner 10 Infrared Radiometer Investigations . . . . . . . . . . . 29

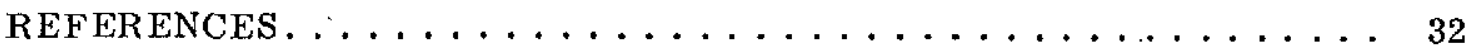

TABLES

Table

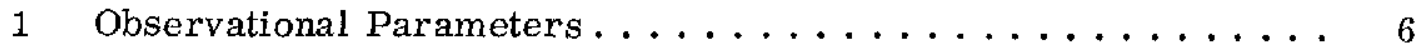

\section{PRECDONG \\ PAGE BLANK NOT FLNADD}




\section{LIST OF ILLUSTRATIONS}

\section{Figure}

1 (a) Venus and (b) lunar uncorrected brightness temperature spectra over the wavenumber range $400-650 \mathrm{~cm}^{-1}$. Atmospheric and telescope transmission characteristics still remain in the spectra. The uncorrected temperatures can be converted to actual brightness temperatures by dividing by the fourth root of the product of atmospheric and telescope transmission functions $\ldots \ldots \ldots \ldots \ldots$

2 (a) Venus and (b) lunar uncorrected brightness temperature spectra over the wavenumber range $750-1250 \mathrm{~cm}^{-1}$. Atmospheric and telescope transmission characteristics still remain in the spectra. The uncorrected temperatures can be converted to actual brightness temperatures by dividing by the fourth root of the product of atmospheric and telescope

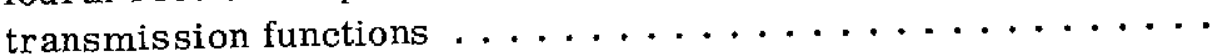

Venus/lunar ratio spectrum, defined by eq. (3), over the wavenumber intervals (a) $450-700 \mathrm{~cm}^{-1}$, (b) $750-1000 \mathrm{~cm}^{-1}$, and (c) $1000-1250 \mathrm{~cm}^{-1}$

Lunar emissivity according to balloon spectroscopy (Murcray, et al., 1970) and laboratory measurements of Apollo 14 lunar soil samples (Logan, et al., 1972) ...............

5 Venus temperature profiles according to Mariner S-band investigations. The Mariner 5 profile is a slightly smoothed average of profiles derived from both ingression and egression data, and is the profile used for quantitative model calculations. The Mariner 10 profile is a straight line approximation of ingression data. $\mathrm{R}=6110 \mathrm{~km}$ is the level to which all opacity

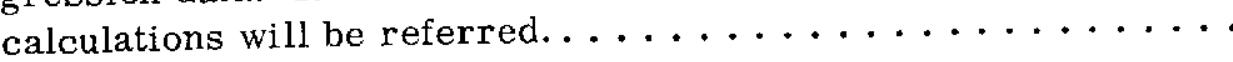

6 Observed Venus/lunar ratio spectrum defined by eq. (3), and two synthetic spectra, considering $\mathrm{CO}_{2}$ as the sole opacity source. Blackbody clouds having tops at $\mathrm{R}=6120$ and $6110 \mathrm{~km}$ form the lower boundaries, and the Mariner 5 data (Fig. 5) provide the temperature profile of the model atmospheres from which the synthetic spectra are computed. There is a displacement of the outer curves relative to the middle curve of one vertical subdivision to enhance readability. The spectral range is $750-1250 \mathrm{~cm}^{-1} \ldots \ldots \ldots \ldots \ldots \ldots \ldots$ 
7 Observed volume extinction coefficient referred to the $\mathrm{R}=6110 \mathrm{~km}$ level. Three lunar surface temperatures are assumed, with $\mathrm{T}_{\mathrm{s}}=360 \mathrm{~K}$ considered the most probable. Unit lunar emissivity is assumed for all three curves. . . . . . . 43

8 The middle curve of Fig. $7\left(\mathrm{~T}_{\mathrm{s}}=360 \mathrm{~K}\right)$ is compared with the volume extinction coefficient calculated for the sulfuric acid cloud model described in the text. The values for the sulfuric acid cloud have been scaled down to two-thirds $(0.67)$ their actual vilue for the purpose of comparison . . . . . . . . . . 44

9 Smoothed freehand versions of the volume extinction coefficient for a lunar surface temperature of $\mathrm{T}_{\mathrm{s}}=360 \mathrm{~K}$. Unit emissivity is assumed for the solid curve, while the lunar emissivity given by the balloon data, Fig. 4, is assumed for the dashed curve. The open circles show the multiple scattering corrections to the solid curve at selected wavenumbers $\ldots \ldots \ldots \ldots$ 


\begin{abstract}
By using the Mariner 5 temperature profile and a homogeneous cloud model, and assuming that $\mathrm{CO}_{2}$ and cloud particles are the only opacity sources, the wavelength dependence of the Venus cloud opacity is inferred from the infrared spectrum of the planet between 450 and $1250 \mathrm{~cm}^{-1}$. Justification for applying the homogeneous cloud model is found in the fact that numerous polarization and infrared data are mutually consistent within the framework of such a model; on the other hand, dense cloud models are not satisfactory.

Volume extinction coefficients varying from $0.5 \times 10^{-5}$ to $1.5 \times 10^{-5} \mathrm{~cm}^{-1}$, depending on the wavelength, are determined at the tropopause level of $6110 \mathrm{~km}$. By using all available data, a cloud mass mixing ratio of approximately $5 \times 10^{-6}$ and a particle concentration of about 900 particles $\mathrm{cm}^{-3}$ at this level are also inferred. The derived cloud opacity compares favorably with that expected for a haze of droplets of a $75 \%$ aqueous solution of sulfuric acid.
\end{abstract}




\section{INTRODUCTION}

The first spectroscopic observations of Venus in the $770-1250 \mathrm{~cm}^{-1}$ range were obtained by Sinton and Strong (1960) in 1953 1957 with spectral resolutions of 8 and $36 \mathrm{~cm}^{-1}$. These spectra indicate a broad depression in the $890 \mathrm{~cm}^{-1}$ $(11.2 \mu \mathrm{m})$ region with the suggestion of a weak $\mathrm{CO}_{2}$ band at $961 \mathrm{~cm}^{-1}$. Advances in detector technology, primarily the development of germanium bolometers cooled to liquid helium temperatures, allowed Gillett, et al. (1968) to make spectral measurements of Venus with a circular variable interference filter, the resolution being $20 \mathrm{~cm}^{-1}$. Both the $890 \mathrm{~cm}^{-1}$ diffuse feature and the 1064 $\mathrm{cm}^{-1} \mathrm{CO}_{2}$ band appear to be present in the spectra. Hanel, et al. (1968) observed the Venus emission spectrum between $750-1250 \mathrm{~cm}^{-1}$ with a Fourier Transform Spectrometer, the spectral resolution being $1.25 \mathrm{~cm}^{-1}$. The $890 \mathrm{~cm}^{-1}$ feature again is evident in the spectrum, with the 791,961 , and $1064 \mathrm{~cm}^{-1} \mathrm{CO}_{2}$ bands possibly being present. In addition to the spectroscopic observations of Venus several radiometric determinations of the brightness temperature of Venus in the terrestrial $10 \mu \mathrm{m}$ atmospheric window (see Pettit, 1961; Sinton, 1963; Murray, et al., 1963; Westphal, et al., 1965) have been made. Most recently Chase, et al. (1974) observed the brightness temperature of Venus at $45 \mu \mathrm{m}$ from the Mariner 10 flyby.

In April 1969, the thermal emission spectra of Venus and the moon were measured at the coude focus of the 107" telescope of the McDonald Observatory. Spectra were recorded from $450-1250 \mathrm{~cm}^{-1}$ with a spectral resolution of $0.67 \mathrm{~cm}^{-1}$. 
The spectral range covers numerous intervals where the earth's atmosphere is sufficiently transparent to permit precise measurements of planetary and lunar intensities. Preliminary results were reported at the Symposium No. 40 of the International Astronomical Union (Hanel, et al., 1971).

The major objectives of the 1969 McDonald observations were:

(1) To obtain adequate spectral resolution and signal-to-noise to positively establish the $\mathrm{CO}_{2}$ bands present in the observed spectral range and their associated rotational line structure,

(2) To search for spectral features of molecules other than $\mathrm{CO}_{2}$, particularly in the diffuse $890 \mathrm{~cm}^{-1}$ absorption feature,

(3) To explore Venus in the $400-600 \mathrm{~cm}^{-1}$ region. Only low resolution radiometry (Low, 1966) has been performed in this region to date, and

(4) To obtain high spectral resolution measurements for a better definition of the Venus "continuum" which should allow investigations of the cloud opacity and composition.

The successful attainment of the fourth objective has made it possible to obtain the wavelength dependence of the cloud opacity in the intermediate infrared. In addition, many other studies have contributed to the growing body of knowledge about the Venus clouds. Among these are studies based on the data provided by the various Mariner and Venera space probes, which contribute information on the temperature profile (Fjeldbo, et al., 1971; Howard, et al., 1974) and molecular composition (Vinogradov, et al., 1968) of the atmosphere, 
as well as information on inhomogeneities within the clouds themselves (Murray, et al., 1974); polarization studies which contribute to the determination of refractive indices and particle sizes (Coffeen and Gehrels, 1969; Hansen and Arking, 1971; Hansen and Hovenier, 1974); spectroscopic studies in the near infrared which provide cloud opacities in this region of the spectrum (Belton, 1968; Belton, et al., 1968); and intermediate infrared limb darkening studies, which provide cloud opacity data complementary to those of the present study (Westphal, 1966; Samuelson, 1968; Chase, et al., 1974).

Each study will be identified and discussed specifically as its role becomes germane to the basic objectives of this paper, which are:

(1) To obtain the cloud opacity in the intermediate infrared as a function of wavenumber.

(2) To obtain the particle number density and mass mixing ratio of cloud material at the Venus tropopause.

(3) To corroborate quantitatively the fit between the wavelength dependence of the cloud opacity and that predicted for a $75 \%$ aqueous solution of sulfuric acid.

(4) To provide quantitative internal consistency checks by intercomparing a variety of independent data within the context of a single homogeneous model.

The observations providing the data necessary to attain the first of these objectives are discussed in the next section. 


\section{OBSERVATIONAL DATA}

A double beam Fourier transform spectrometer of the type described by Hanel, et al (1969) was modified for these observations. First, the spectral range was extended to the long wave-length limit of the beam splitter substrate (potassium bromide) by the use of copper-doped germanium detectors. Second, the spectral resolving capability of the instrument was increased by a new drive system which permitted movements of the Michelson mirror up to several centimeters. Third, the motion of the auxiliary mirrors used for calibration purposes was automated.

The Venus spectra were obtained shortly after inferior conjunction at a phase angle of $204^{\circ}$. Only 0.04 of the apparent disk was illuminated. The angular diameter of Venus was $56^{\prime \prime}$ and the instrumental field of view 31 " with guiding centered on the disk. The spectra thus pertain to the central third of the dark side of Venus, including zenith angles up to $34^{\circ}$. The measured spectra are the difference between recordings made while the field of view was centered on the disk and on the sky immediately adjacent. Sky and telescope emission has therefore been eliminated but not the transmission of the Earth atmosphere and the telescope. The spectra have been normalized against spectra of blackbodies. The measured spectrum is therefore

$$
F_{o b s}^{v}(\nu)=F_{\nu}^{v} \breve{a t m}_{\text {ate }}^{v}
$$


where $F_{\nu}^{v}$ is the spectrum of Venus and $g_{\text {atm }}^{v}$ and $g_{t c 1}^{v}$ are the atmospheric and telescope transmissions respectively.

Spectra of the moon have been obtained under similar observing conditions to remove the transmission effects of the atmosphere and of the telescope. The lunar surface at temperature $T_{\mathrm{s}}$ and with spectral emissivity $\epsilon_{\mathrm{s}}$ emits radiation $\epsilon_{\mathrm{s}} \mathrm{B}_{\nu}\left(\mathrm{T}_{\mathrm{s}}\right)$. The measured lunar spectrum is then

$$
\mathrm{F}_{\mathrm{obs}}^{\mathrm{M}}(\nu)=\epsilon_{\mathrm{s}}(\nu) \mathrm{B}_{\nu}\left(\mathrm{T}_{\mathrm{s}}\right) \mathrm{J}_{\mathrm{atm}}^{\mathrm{M}} \mathrm{J}_{\mathrm{te} 1}^{\mathrm{M}}
$$

Lunar highlands observed at a phase angle of $52^{\circ}$ and with a $51^{\prime \prime}$ field of view served as the comparison object. The observational parameters are summarized in Table I. The time $t$ is the integration time for each object.

The measured Venus and lunar spectra are displayed in terms of brightness temperature in Figs. 1 and 2. The spectral resolutions is $0.67 \mathrm{~cm}^{-1}$ for both cases with apodization applied. Many of the observed spectral features are associated with the transmission of the Earth atmosphere. Rotational lines of water vapor, the $667 \mathrm{~cm}^{-1} \mathrm{CO}_{2}$ and the $1042 \mathrm{~cm}^{-1} \mathrm{O}_{3}$ bands are evident. The ratio of the Venus to the lunar measurement should be free of telluric effects in first order and yields the Venus spectrum relative to the moon,

$$
\mathbf{F}_{\nu}^{v}=\left(\frac{\mathbf{F}_{\mathrm{abs}}^{v}(\nu)}{F_{\mathrm{obs}}^{\mathrm{M}}(\nu)}\right) \epsilon_{\mathrm{s}}(\nu) \mathrm{B}_{\nu}\left(\mathbf{T}_{\mathrm{s}}\right)
$$

The telescope transmission has been assumed equal in both cases. 
Table I

Observational Parameters

\begin{tabular}{|c|c|l|c|c|c|c|c|}
\hline & $\begin{array}{c}\text { Local } \\
\text { Time } \\
(\mathrm{hr}: \mathrm{min})\end{array}$ & Object & $\begin{array}{c}\text { Number } \\
\text { of } \\
\text { Spectra }\end{array}$ & $\begin{array}{c}\mathrm{t} \\
\text { (min.) }\end{array}$ & $\begin{array}{c}\text { Z.A. } \\
\text { (deg.) }\end{array}$ & $\begin{array}{c}\text { FOV } \\
\text { (arc sec) }\end{array}$ & $\begin{array}{c}\text { Object } \\
\text { Diam } \\
\text { (arc sec) }\end{array}$ \\
\hline April 20, '69 & $11: 10-11: 40$ & Venus & 48 & 29.2 & 23 & 31 & 56 \\
April 27, '69 & $23: 00-23: 20$ & Moon & 32 & 19.5 & 34 & 51 & 1856 \\
\hline
\end{tabular}


From the available data, a set of Venus and lunar spectra were selected for which the amount of water vapor in the atmosphere above the observatory was nearly the same for both measurements. The criterion adopted for selecting the best set of spectra was to minimize the residual effect of the terrestrial lines in the ratio spectrum. Residual terrestrial water vapor lines, due to incomplete cancellation of the atmospheric transmission, are still noted in the ratio shown in Fig. 3. These residuals are too small to affect the results in the $750-1250 \mathrm{~cm}^{-1}$ region significantly, although they may have a noticeable effect in the $450-600 \mathrm{~cm}^{-1}$ range. For the selected sets of spectra atmospheric transmittances are approximately equal and then their ratio may be taken equal to unity.

Further uncertainties in the derived Venus spectrum arise from inadequate knowledge of the lunar surface temperature and emissivity. A value of $T_{s}=360 \mathrm{~K}$ was obtained by interpolation with respect to phase and location on the lunar surface from the brightness temperature contours of Montgomery, et al. (1966). Due to possible uncertainties in the absolute values of these temperatures, the adopted value of $360 \mathrm{~K}$ is also uncertain. A $20 \mathrm{~K}$ error in the lunar temperature estimate would translate into a $10 \mathrm{~K}$ error in the Venus spectrum and could also introduce a small relative error in the spectrum that varies slowly with wavenumber.

The lunar emissivity problem is more difficult to treat. Lunar investigations (Murcray, et al., 1970) indicate significant deviations of the lunar material 
from blackbody behavior. Murcray, et al. have inferred an emissivity for the central highlands from measurements with a balloon-borne spectrometer. This emissivity, taken from Fig. 2 of Murcray, et al. and for a $180 \mathrm{sec}$ of arc field of view, is plotted in Fig. 4. The small scale features are probably not real; they are considered to be residuals which were not removed by the instrumental calibration (Salisbury, private communication 1973). The lunar surface emissivity could not be determined in the $1042 \mathrm{~cm}^{-1}$ region due to absorption by telluric ozone. The dotted line represents an estimate for this region; the actual values are of little significance as the telluric ozone absorption also blocks the Venus spectrum in this region. Laboratory measurements of Apollo lunar soil samples indicate a different non-blackbody behavior; the emissivity for an Apollo 14 soil sample (Logan, et al., 1972) is shown in Fig. 4 for comparison.

In the following calculations the lunar emissivity first will be assumed to be unity. Later, in Section 7 , it will be shown that substituting the emissivity values of Murcray, et al. has no significant effect on the conclusions reached in this paper.

Various spectral features, evident in the observed spectrum, can be associated with Venus with reasonable certainty:

(1) The $\mathrm{CO}_{2}$ bands at $791,828,865$, and $961 \mathrm{~cm}^{-1}$ which appear in absorption; the rotational structure of the 791 and $961 \mathrm{~cm}^{-1}$ bands is well resolved.

(2) The continuum which varies slowly throughout most of the spectral region; a particularly strong diffuse feature lies between 875 and $925 \mathrm{~cm}^{-1}$. 
The first point mentioned above indicates a negative temperature gradient with height, while the second point indicates the importance of the clouds in defining the thermal continuum. However, in order to interpret the spectrum quantitatively with respect to the cloud particle properties, the effect of $\mathrm{CO}_{2}$ absorption has to be removed. This will be accomplished with the radiative transfer model discussed in the next section.

\section{RADIATIVE TRANSFER MODEL}

The observed spectrum (Fig. 3) represents the radiation field at the top of the Venus atmosphere. Radiation originates at all levels within the atmosphere and is transfered outward according to the opacity of these levels as expressed by the equation of radiative transfer,

$$
\mathrm{I}_{\nu}(0, \mu)=\int_{0}^{\infty} \mathrm{B}_{\nu}\left(\tau_{\nu}\right) \mathrm{e}^{-\tau_{\nu} / \mu} \frac{\mathrm{d} \tau_{\nu}}{\mu}
$$

$\mathbf{I}_{\nu}$ is the specific intensity of the outgoing radiation field as a function of direction cosine $\mu, \mathrm{B}_{\nu}$ is the Planck function in intensity units, and

$$
\tau_{\nu}=\int_{z}^{z} c\left(k_{\mathrm{g}} \rho+\mathrm{N}_{\mathrm{p}} \chi_{\mathrm{E}}\right) \mathrm{d} \mathrm{z}
$$

is the optical depth. The volume extinction coefficient is separated into a molecular gas component, $\mathrm{k}_{\mathrm{g}} \rho$, and a cloud particle component, $\mathrm{N}_{\mathrm{p}} \chi_{\mathrm{E}}$, where $\mathrm{k}_{\mathrm{g}}$ and $\rho$ are the corresponding mass absorption coefficient and gas density, and $\mathrm{N}_{\mathrm{p}}$ and $\chi_{\mathrm{E}}$ are the particle number density and mean particle extinction cross-section, respectively. The role of scattering is ignored at this stage, but it will be demonstrated in Section 7 that this assumption is justified. 
When the optical axis of the observing system is centered on the planetary disk, the observable quantity is

$$
\mathrm{F}_{\nu}=\frac{2}{1-\mu_{\min }} \int_{\mu_{\mathrm{min}}}^{1} \mathrm{I}_{\nu}(0, \mu) \mu \mathrm{d} \mu,
$$

where $\mu_{\min }$ equals zero if the planetary disk is entirely contained in the field of view, and equals 0.83 in the present case with a $34^{\circ}$ angle between the normal to the planetary surface at the edge of the field of view and the view direction. Equation (6) assumes axial symmetry of $I_{\nu}(0, \mu)$ about the optical axis, which may not always be strictly valid because of possible horizontal inhomogeneities in the planetary atmosphere being observed.

All quantities in eqs. 4 to 6 are either known from observations or can be derived from theory except for the product $\mathrm{N}_{\mathrm{p}} \mathrm{X}_{\mathrm{E}}$. One of the main purposes of this paper is to derive $\mathrm{N}_{\mathrm{p}} \chi_{\mathrm{E}}$ and interpret it in terms of the number density and composition of the Venus cloud particles.

The pressure, temperature and density relationships with height have been taken from the results of the Mariner 5 S-band investigation (Fjeldbo, et al., 1971). The adopted temperatures, shown in Fig. 5, are a slightly smoothed average of the ingression and egression profiles. Inherent in the derived temperatures are the assumptions of a $0.95 \mathrm{CO}_{2}$ mixing ratio and the applicability of the perfect gas law. 
For computational feasibility the atmosphere was divided into 29 equal, one kilometer thick layers between planetary radii of $6111 \mathrm{~km}$ and $6140 \mathrm{~km}$. At the lower boundary between $6100 \mathrm{~km}$ and $6111 \mathrm{~km}$ there are three additional layers, one $3 \mathrm{~km}$ and two $4 \mathrm{~km}$ thick. Each layer in this model is assumed to be isothermal. The upper $(R=6140 \mathrm{~km})$ and lower boundaries $(R=6100 \mathrm{~km})$ of the model atmosphere are arbitrary. At the upper boundary, checks were made to ensure that adding layers did not increase the opacity. At the lower boundary the atmospheric model is not completely opaque at all wavenumbers for a pure $\mathrm{CO}_{2}$ atmosphere; however, it was found that a substantial absorber had to be introduced into the model to yield computed spectra resembling the measured one, and with this absorber the model atmosphere is virtually opaque at all wavenumbers. Therefore it is not required to extend the model below this otherwise arbitrary lower boundary.

$\mathrm{CO}_{2}$ transmission functions were generated for the above model using a direct integration procedure (Kunde and Maguire, 1974). The monochromatic transmission functions were computed and averaged over wavenumber intervals $\Delta \nu=0.1 \mathrm{~cm}^{-1}$, and then stored on tape for subsequent solutions of eq. (4). In order to make a direct comparison with the observations, eq. (6) was solved with $\mu_{\text {min }}=\cos 34^{\circ}$, which is the direction cosine of the zenith angle at the edge of the field of view. Finally, the theoretical spectra have been degraded to $0.67 \mathrm{~cm}^{-1}$, the resolution of the observed spectrum, by convolving $\mathrm{F}_{\nu}$ with the instrument function. With the help of this model it is possible to synthesize 
spectra with different cloud properties which can then be compared to the measured spectra.

\section{ATMOSPHERIC AND CLOUD OPACITY}

An approximate agreement between observed and calculated spectra can be reached simply by assuming $\mathrm{CO}_{2}$ to be the sole source of opacity and vertically adjusting the top of a very dense black cloud. Specifically, this requires $\mathrm{N}_{\mathrm{p}} \chi_{\mathrm{E}}=0$ in eq. (5) above the cloud top, and very large (i.e. $\mathrm{N}_{\mathrm{p}} \chi_{\mathrm{E}} \geq 10^{-2} \mathrm{~cm}^{-1}$ ) below the cloud top.

Figure 6 gives the comparisons among the observed spectrum and the spectra computed for different cloud altitudes. There is fair agreement between the observed spectrum and the theoretical one corresponding to a cloud top at $\mathrm{R}=6120 \mathrm{~km}$, in the sense that the absolute levels and $\mathrm{CO}_{2}$ band strengths are similar. However, it is also clear that the continuum of the observed spectrum cannot be explained by a $\mathrm{CO}_{2}$ atmosphere and a black dense cloud alone.

The dips in the observed continuum at 905 and $1050 \mathrm{~cm}^{-1}$ could be explained with a cloud emissivity on the order of 0.8 at these points. However, it has been demonstrated (Samuelson, 1969) that this would imply particle single-scattering albedos $\widetilde{\omega}_{0} \sim 0.7$. It has also been shown.(Samuelson, 1968) that, on the average, $\widetilde{\omega}_{0} \lesssim 0.2$ for Venus. While it is not completely correct to compare these numbers directly, the large disparity between the two numbers tends to preclude cloud emissivity variations as an explanation of the observed undulations of the 
continuum. A much more reasonable alternative is provided by a wavenumberdependent opacity coupled with a vertical temperature gradient.

It will be assumed that the disparity between observed and theoretical spectral continua, shown in Fig. 6, can be resolved with a model consisting of a homogeneous mixture of cloud particles and atmospheric gas. It is realized that both this model and the previous one represent idealized conditions, with reality being somewhere in between. It is also realized that later refinements may be both desirable and necessary. The radiative transfer model, described in the previous section and used below, assumes that only $\mathrm{CO}_{2}$ and the cloud particles are responsible for the atmospheric opacity. Finally, it is assumed that scattering does not play an important role in the radiative transfer problem, and hence the form of eq. (4) may be retained without modification.

The only remaining parameter that is required to define completely the radiative transfer problem is the assignment of the cloud volume extinction coefficient $\mathrm{N}_{\mathrm{p}} \chi_{\mathrm{E}}$ at some specified level. This special value will be called $\left(N_{P} \chi_{E}\right)_{0}$ and has been chosen to refer to $R=6110 \mathrm{~km}$. According to Fig. 5 , this level corresponds closely to the tropopause of Venus. The requirement of atmospheric homogeneity then automatically specifies $N_{p} \chi_{E}$ at every other level.

To find the value of $\left(\mathrm{N}_{\mathrm{p}} \chi_{\mathrm{E}}\right)_{0}$ at each wavenumber which produces the flux in the measured spectrum at the same wavenumber required several estimates 
for $\left(\mathrm{N}_{\mathrm{p}} \chi_{\mathrm{E}}\right)_{0}$ to be made and inserted into eqs. (5), (4), and finally (6). Quadratic interpolation was then used to obtain the value of $\left(\mathrm{N}_{\mathrm{p}} \chi_{\mathrm{E}}\right)_{0}$ that gave perfect agreement between calculated and observed $\mathrm{F}_{\nu}$. The calculations were carried out every $0.1 \mathrm{~cm}^{-1}$.

The derived values of $\left(\mathrm{N}_{\mathrm{p}} \chi_{\mathrm{E}}\right)_{0}$ are shown in Fig. 7 for three lunar temperatures, the best estimate value of $360 \mathrm{~K}$ and temperatures $20 \mathrm{~K}$ to either side representing possible uncertainties in lunar temperature. The regions 550$750 \mathrm{~cm}^{-1}$ and $1035-1065 \mathrm{~cm}^{-1}$ are largely void of data because of terrestrial $\mathrm{CO}_{2}$ and $\mathrm{O}_{3}$, respectively. The lunar emissivity was assumed to be unity. As will be shown in Section 7, correcting for lunar emissivity does not appear to affect the results in any important aspect, and it is believed that Fig. 7 gives a sufficiently accurate representation of the opacity properties of the Venus clouds.

Residual spectral lines of the 791,828 and $964 \mathrm{~cm}^{-1} \mathrm{CO}_{2}$ bands are evident, indicating trace effects of telluric $\mathrm{CO}_{2}$ absorption or inadequacies in the Venus model. These small scale residuals do not affect the conclusions that will be based mainly on the large scale cloud opacity features. The derived results for $\left(N_{p} \chi_{E}\right)_{0}$ are sufficient to define a smooth opacity continuum. Even under the worst conditions, the r.m.s.-value of the residual fluctuations is on the order of $0.1\left(\mathrm{~N}_{\mathrm{p}} \chi_{\mathrm{E}}\right)_{0}$, thus making the uncertainty of the smoothed $\left(\mathrm{N}_{\mathrm{P}} \chi_{\mathrm{E}}\right)_{0}$, within the limitations of the model, consider ably less than $10 \%$. 
The volume extinction coefficient shows a general increase by a factor of two from low to high wave numbers. In addition to the slowly varying component, there are two relatively narrow features centered approximately at $905 \mathrm{~cm}^{-1}$ and $1050 \mathrm{~cm}^{-1}$, although the latter is less certain than the former because of the proximity of the $1042 \mathrm{~cm}^{-1}$ terrestrial $\mathrm{O}_{3}$ band. A third possible, but much broader feature, lies between 1115 and $1225 \mathrm{~cm}^{-1}$. It is difficult at this stage to determine whether the features are caused by absorption due to the bulk material or to trace contaminants within the clouds.

The volume extinction coefficient $\left(\mathrm{N}_{\mathrm{p}} \chi_{\mathrm{E}}\right)_{0}$ at $\mathrm{R}=6110 \mathrm{~km}$ varies between $0.5-1.5 \times 10^{-5} \mathrm{~cm}^{-1}$ according to Fig. 7. The reciprocal of this number, the photon mean free path length, $\ell$, varies between 0.7 and $2 \mathrm{~km}$ at the same level, which is well within the cloud system in this model. The clouds are thus inferred to be of the nature of a tenuous haze rather than that of a dense cloud.

It is useful to compare these results with those obtained from limb darkening analyses of Venus. One analysis (Samuelson, 1968) is concerned with observations over the $8-14 \mu \mathrm{m}$ spectral interval (Westphal, 1966). Another is based on results from the infrared radiometry investigation of Mariner 10 (Chase, et al., 1974) covering the $35-55 \mu \mathrm{m}$ spectral region.

According to the first analysis, the optical thickness, $\tau_{1}$, of the atmosphere above the tropopause which is contributed by the particles alone is approximately 1.3. A simple expression equivalent to one used by Gierasch and Goody (1970), 


$$
\tau_{1}=\left(\mathrm{N}_{\mathrm{p}} \chi_{\mathrm{E}}\right)_{0} \mathrm{H}
$$

relates this optical depth to the scale height, $\mathrm{H}$, which is taken to be $5 \mathrm{~km}$. Eq. (7) then yields $\left(\mathrm{N}_{\mathrm{p}} \chi_{\mathrm{E}}\right)_{0}=0.26 \times 10^{-5} \mathrm{~cm}^{-1}$, which is about a factor of four less than the mean value over this spectral interval indicated by Fig. 7. The agreement is only fair, and it is difficult to state whether the difference is indicative of uncertainties in the methods or due to real temporal differences in the atmosphere.

The second limb darkening analysis is based on the Mariner 10 infrared (35 - $55 \mu \mathrm{m}$ ) radiometry investigation (Chase, et al., 1974). The authors, using their own data and an assumed lapse rate of $9 \mathrm{~K} \mathrm{~km}^{-1}$, obtain a volume extinction coefficient of $0.24 \times 10^{-5} \mathrm{~cm}^{-1}$ at the $222 \mathrm{~K}$ temperature level. Their analysis is internally consistent, though it is not consistent with a homogeneous atmosphere having a constant lapse rate. Thus, it is not possible to scale their result to the Venus tropopause using the model of the present paper.

Because of this the analysis of the Mariner 10 radiometer data has been carried out in a manner consistent with a homogeneous model. An outline of the procedure is given in the Appendix. From this procedure, and using a lapse rate of $5 \mathrm{~K} \mathrm{~km}^{-1}$, which is an average value consistent with the Mariner 10 radio science data at these levels, one obtains a tropopause volume extinction coefficient (nominally for $220 \mathrm{~cm}^{-1}$ ) of

$$
\left(\mathrm{N}_{\mathrm{p}} \chi_{\mathrm{E}}\right)_{0}=3 \times 10^{-6} \mathrm{~cm}^{-1}
$$


If the lapse rate of $9 \mathrm{~K} \mathrm{~km}^{-1}$ suggested by Chase, et al. had been used, an extinction coefficient of $5 \times 10^{-6} \mathrm{~cm}^{-1}$ would have been obtained. Finally, if a lapse rate on the order of $4.6 \mathrm{~K} \mathrm{~km}^{-1}$ or less had been used, it would have been impossible to obtain an internally consistent interpretation of the Mariner 10 radiometer data for reasons given in the Appendix. Since this lower limit is rather close to the average lapse rate at the levels of interest implied by the Mariner 10 radio science investigation, it would be instructive to carry out the analysis with a more sophisticated model than has been considered here. Even so, the two values for the volume extinction coefficient listed above are certainly consistent with the value one would expect at $220 \mathrm{~cm}^{-1}$ by extrapolating the curves in Fig. 7.

A word of caution is in order. Radically different interpretations of the same data can be obtained simply by assuming different models; thus the solutions are quite non-unique. On the other hand, the separate determinations of the opacity by quite different methods using different data tend to corroborate one another within the context of a single homogeneous model, lending some support to the legitimacy of the concept itself. In any event, the homogeneous model will be retained for the purpose of estimating the cloud mass mixing ratio, discussed in the next section. 


\section{CLOUD MASS MIXING RATIO}

The ratio of cloud material relative to the gaseous atmosphere is a quantity of basic importance. According to quite general arguments by Gierasch and Goody (1970), the cloud material should be almost fully condensed. Hence a determination of the cloud particle mass mixing ratio, $q_{p}$, will determine essentially the mixing ratio of the substance itself, regardless of phase.

Two separate quantities are needed for this determination, the size distribution and the number density at some reference level. The assumption of homogeneity will then allow a determination of the mass mixing ratio.

Of course, as the results of Mariner 10 have so clearly shown, there are many inhomogeneities in the clouds of Venus. The television camera in particular has shown horizontal cloud structure in the ultraviolet, and vertical structure (layering) in both the orange and ultraviolet (Murray, et al., 1974). However, it is difficult to determine what the contrast in the pictures implies about actual particle density or size variations, particularly because the pictures are strongly computer enhanced. Murray, et al. point out that the clouds extend to heights corresponding to the 10 to $90 \mathrm{mb}$ pressure range, and that a general lack of shadowing in pictures of the terminator is consistent with the presence of an enveloping thin haze, as opposed to dense vertical columns. Finally they state that preliminary measurements of curvature of the limb in selected frames imply that the haze layers, in both the ultraviolet and orange, extend to a radius of about $6130 \mathrm{~km}$. 
On the other hand the results of the infrared radiometry experiment (Chase, et al., 1974) indicate that the bulk of thermal emission between 35 and $55 \mu \mathrm{m}$ originates at least 10 to $15 \mathrm{~km}$ below the $\mathrm{R}=6130 \mathrm{~km}$ level. This follows from comparing the brightness temperature at normal incidence $\left(\mathrm{T}_{\mathrm{B}}=255 \mathrm{~K}\right)$ with the temperature profile inferred from the Mariner 10 radio science investigation (Howard, et al., 1974; see Fig. 5 this paper). Chase, et al. also point out that deviations of the limb scan from a smooth curve are on the order of one part in 200 , implying a rather horizontally uniform atmosphere at thermal wavelengths.

Thus, even though inhomogeneities are known to exist in the Venus cloud structure, there is evidence that they may not be so severe as to come into serious conflict with a homogeneous model. Also, certain quantities, such as the particulate mass mixing ratio, are important mainly in the mean; and the mean values should be fairly independent of the degree of homogeneity. The same should be true, apart from an unkmown scaling factor, for the wavelength variation of the intermediate - IR volume extinction coefficient (Fig. 7). Thus what follows will always assume homogeneity.

From polarization data (Coffeen and Gehrels, 1969), Hansen and Arking (1971) have deduced a refractive index of 1.44 at $\lambda=5500 \AA$ and a mean particle radius of $\mathrm{a}=1.1 \mu \mathrm{m}$. Later Hansen and Hovenier (1974), using a particle size distribution of the form

$$
N(r)=C r^{\frac{1-3 b}{b}} e^{-\frac{r}{a b}}
$$


deduced a mean particle radius of $\mathrm{a}=1.05 \mu \mathrm{m}$ and a parameter $\mathrm{b}=0.07$, where $\mathrm{b}$ is related to the dispersion of particle sizes about the mean. Combining the known refractive index with eq. (9), the Mie theory yields a mean scattering cross-section per particle in the visible region of the spectrum of

$$
\chi_{\mathrm{s}}=0.6 \times 10^{-7} \mathrm{~cm}^{2}
$$

Thus the polarization data have yielded both a mean particle size and scattering cross-section. The last quantity needed for a determination of the mass mixing ratio is the number density, $\mathrm{N}_{\mathrm{p}}$. Since $\chi_{\mathrm{s}}$ is already known from eq. (10), a determination of the volume scattering coefficient, $\mathrm{N}_{\mathrm{p}} \chi_{\mathrm{s}}$, will suffice for obtaining $\mathrm{N}_{\mathrm{p}}$.

The scattering cross-section is approximately wavelength independent as long as the particle is larger than the wavelength. Thus, values of $\chi_{\mathrm{s}}$ should be comparable in the visible and near infrared, and the polarization data and near-IR reflection spectra should refer, approximately, to the same crosssection. A very useful approximate expression relating to the near-IR spectra is

$$
\mathrm{N}_{\mathrm{p}} \chi_{\mathrm{s}}=\left(\frac{273}{\mathrm{~T}} \mathrm{f}_{\mathrm{co}_{2}}\right)\left(\frac{\mathrm{P}}{\mathrm{M}}\right)\left(\frac{1}{1-\langle\cos \theta\rangle}\right)
$$

where $\mathrm{N}_{\mathrm{p}} \chi_{\mathrm{s}}$ is the volume scattering coefficient associated with the atmospheric level designated by the pressure $P$ and temperature $T$, and $f_{\mathrm{CO}_{2}}=0.95$ is the volume mixing ratio of $\mathrm{CO}_{2}$. The quantity $\mathrm{M}$ is called the "specific amount" of 
$\mathrm{CO}_{2}$, and is the number of atm-cm of $\mathrm{CO}_{2}$ contained in one mean free path length, $\ell$.

The first two factors in parentheses on the right hand side of (11) were developed by BeIton, et al. (1968) in the context of isotropic scattering. The factor $(1-\langle\cos \theta\rangle)^{-1}$, where $\theta$ is the scattering angle related to the singlescattering phase function, was introduced by Hansen (1969) to account approximately for anisotropic scattering. The practical justification for Hansen's approximation was given earlier by Potter (1969), who first examined numerically the efficacy of approximate treatments of extreme forward scattering.

It has been shown by Belton, et al. (1968) that an analysis of near-IR $\mathrm{CO}_{2}$ reflection spectra will yield $\mathrm{T}, \mathrm{P}$, and $\mathrm{M}$. The most definitive results have been obtained by Belton (1968), who recommends $\mathrm{P}=0.2 \mathrm{~atm}, \mathrm{~T}=250^{\circ} \mathrm{K}$, and $M=2 \times 10^{4} \mathrm{~cm}$-atm., but also suggests that the ratio $\mathrm{P} / \mathrm{M}$ is probably accurate only to within a factor of two. Also, using the results of the polarization data (Hansen and Hovenier, 1974), in conjunction with eq. (9) and the Mie theory, it is found that $\langle\cos \theta\rangle$ is approximately 0.7 . Combining the near infrared and polarization results yields $N_{p} X_{s}$ equal to $3.45 \times 10^{-5} \mathrm{~cm}^{-1}$ at a pressure level of $0.2 \mathrm{~atm}$. Because $\mathrm{N}_{\mathrm{p}} \chi_{\mathrm{s}}$ is proportional to the gas density according to the homogeneous model, it is legitimate to scale $\mathrm{N}_{\mathrm{p}} \chi_{\mathrm{s}}$ linearly with density to the $\mathrm{R}=6110 \mathrm{~km}$ level in order to make it consistent with the extinction coefficients shown in Fig. 7. This yields 


$$
\left(\mathrm{N}_{\mathrm{p}} \chi_{\mathrm{s}}\right)_{0} \sim 5.5 \times 10^{-5} \mathrm{~cm}^{-1}
$$

By comparing (10) with (12) one obtains a particle number density at the tropopause of

$$
\left(\mathrm{N}_{\mathrm{p}}\right)_{0} \sim 900 \text { particles } \mathrm{cm}^{-3}
$$

It is well-established that $\chi_{s}$, for all practical purposes, is also the extinction cross-section in the visible, since absorption is negligible in comparison with scattering in this spectral region. Hence eq. (12) and Fig. 7 provide a direct comparison of radiative cross-sections in the visible and intermediate infrared. The comparison yields $\chi_{\mathrm{s}} \sim 5-10 \chi_{\mathrm{E}}$, a result completely consistent with micron-size particles, since the radiative-to-geometrical cross-section ratio approximates unity only as long as the wavelength is smaller than the particle; once the wavelength becomes larger the ratio decreases rapidly. Even though this statement is qualitative and depends strongly on refractive index, the relative values of the cross-sections seem quite reasonable, implying internal consistency among the analyses of the near-IR, intermediate-IR, and polarization data in the visible.

The general consistency of the various observations considered in the context of a simple homogeneous model implies that realistic determination of the mass mixing ratio for the cloud particles can be obtained. Taking the particle distribution given by eq. (9), the number density $\left(\mathrm{N}_{\mathrm{p}}\right)_{0} \sim 900$ particles $\mathrm{cm}^{-3}$ given by eq. (13), and assuming a bulk density of $1 \mathrm{~g} \mathrm{~cm}^{-3}$ for the particles, one 
arrives at a particle mass mixing ratio at the tropopause of

$$
\mathrm{q}_{\mathrm{p}} \sim 5 \times 10^{-6} \mathrm{~g} / \mathrm{g} .
$$

As mentioned before, Gierasch and Goody (1970) state that the clouds should be essentially fully condensed at the levels in question. Thus, the mixing ratio of $5 \times 10^{-6}$ should closely represent the entire quantity of material involved, vapor plus liquid or solid, and the vapor mixing ratio should be considerably less $\left(q_{v} \ll 5 \times 10^{-6}\right)$. This latter, of course, is the only mixing ratio that can be determined spectroscopically. Gierasch and Goody also point out that such a low mixing ratio can have only a negligible effect on the adiabatic lapse rate (it will be essentially the dry rate) and any changes in temperature gradient could conceivably produce, but not be caused by, condensation of vapor into clouds.

\section{SULFURIC ACID}

The derived volume extinction coefficient will now be compared with that predicted for droplets of $\mathrm{H}_{2} \mathrm{SO}_{4}$ solutions, which is presently a promising candidate for the Venus cloud composition [cf. Young and Young (1973), Sill (1972), and Young $(1973,1974)]$. The complex refractive index of $\mathrm{H}_{2} \mathrm{SO}_{4}$ has been obtained in the laboratory by Remsberg (1973) over the wavenumber interval 747 to $1570 \mathrm{~cm}^{-1}$ for two concentrations, $75 \%$ and $90 \%$. Only the $75 \%$ solution shall be considered because, as Young (1974) has pointed out, the 90\% solution quite clearly shows a qualitatively incorrect wavenumber dependence of the 
opacity. Using the size distribution obtained from the polarization data [eq. (9)], and the number density from eq. (13), the Mie theory was used to calculate volume extinction coefficients at selected wavenumbers, normalized to $\mathrm{R}=6110 \mathrm{~km}$.

The results, reduced by a factor 1.5 to allow a more readable comparison with cloud opacities inferred from the observations, are shown in Fig. 8 as a smooth solid curve. The comparis on data are the same as the middle curve of Fig. 7, with $T_{\mathrm{s}}=360 \mathrm{~K}$. It should be emphasized that the two curves are derived completely independently of each other, except for the assumed $95 \% \mathrm{CO}_{2}$ abundance common to both data sets. It should also be remembered that absolute errors on the order of factors of two are to be expected for both data sets; thus the good agreement between both opacity derivations lends support to the sulfuric acid cloud hypothesis. Conversely, if sulfuric acid is assumed to be the case for the Venus clouds, the agreement shown in Figure 8 tends to support the model and analyses performed previously.

\section{LUNAR EMISSIVITY AND MULTIPLE SCATTERING CORRECTIONS}

Two corrections that have not received adequate attention up to now are connected with the lunar emissivity and multiple scattering in the Venus clouds. Fortunately, as will be shown below, neither appears to be particularly important. 


\section{A. Lunar Emissivity}

The lunar emissivity was assumed to be unity in eq. (3) in deriving the volume extinction coefficients shown in Figs. 7 and 8 . A smooth freehand version of Fig. 8 is shown in Fig. 9 by the solid curve. The dashed curve is the freehand approximation of the volume extinction coefficient determined by correcting for lunar emissivity according to Murcray, et al. (1970); the emissivity shown in Fig. 4 was incorporated into eq. (3). As is evident from Fig. 9, the qualitative shapes of the curves are similar, while the differences in absolute values are well within the uncertainties of the values themselves. Thus, correcting for effects of lunar emissivity does not change any of the previous conclusions.

\section{B. Multiple Scattering}

The last correction to be discussed is concerned with the role of scattering in the transfer problem. An approximate allowance can be made for scattering by treating the atmosphere as homogeneous, and solving the more complete problem at selected wavenumbers. It was decided to evaluate the singlescattering albedo of a volume element (gas plus cloud particles) at optical depth unity, and to require that this value be constant at all levels for the wavenumber in question. This is not strictly legitimate because generally the $\mathrm{CO}_{2}$ opacity is not proportional to the density; however, since the $\mathrm{CO}_{2}$ opacity is of minor, though far from negligible, importance at the wavenumbers of concern, the approximation should be fairly good. The required single-scattering particle 
albedos were computed for sulfuric acid droplets having a size distribution given by eq. (9). The cloud volume extinction coefficients, however, were adopted from the observed curve in Fig. 8, instead of the curve for sulfuric acid.

The complete multiple scattering problem was solved by the method of discrete ordinates in the seventh approximation (Samuelson, 1969). At each wavenumber considered the optical depth for the combined " $\mathrm{H}_{2} \mathrm{SO}_{4}-\mathrm{CO}_{2}$ " cloud-gas system was determined as a function of height. The single-scattering phase function was determined from the Mie theory combined with eq. (9). The depth independent single-scattering albedo was evaluated at optical depth unity at each wavenumber. The Mariner 5 temperature profile (Fig. 5) was approximated by a fourth-degree power series in $\tau$. The discrete ordinate method was then used to solve the multiple scattering problem at each wavenumber. Selected wavenumbers assuming a lunar surface temperature of $360 \mathrm{~K}$ and emissivity of unity, and using the more complete scattering theory, are plotted in Fig. 9 with open circles. The deviations from the solid curve are slight, indicating that scattering does not introduce any major modifications to the derived volume extinction coefficients. Of course the results are strictly valid only for $\mathrm{H}_{2} \mathrm{SO}_{4}$ solution droplets; nevertheless they imply a general justification for neglecting scattering as long as the refractive indices of the material are not drastically different from those of $\mathrm{H}_{2} \mathrm{SO}_{4}$ solutions. 


\section{SUMMARY}

The thermal infrared spectrum of Venus has been recorded from 450 to $1250 \mathrm{~cm}^{-1}$, with a gap covering the range 600 to $725 \mathrm{~cm}^{-1}$ due to terrestrial $\mathrm{CO}_{2}$, and gaps from 1030 to $1042 \mathrm{~cm}^{-1}$ and 1045 to $1063 \mathrm{~cm}^{-1}$ due to terrestrial $\mathrm{O}_{3}$. The spectral resolution is $0.67 \mathrm{~cm}^{-1}$.

With the help of a homogeneous model atmosphere, the Venus cloud volume extinction coefficient has been obtained, normalized to a radius $\mathrm{R}=6110 \mathrm{~km}$, as a function of wavenumber (Fig. 7). Several conclusions were drawn from this analysis. First, there is a general increase of about a factor 2 in the volume extinction coefficient from small to large wavenumbers. Qualitatively this is to be expected for particles smaller than the wavelength of radiation. Second, there are absorption features at 905 and $1050 \mathrm{~cm}^{-1}$, with possibly a much broader one covering the range from 1115 to $1225 \mathrm{~cm}^{-1}$. It is not possible to determine whether these features correspond to regions of anomalous dispersion of the primary cloud constituent, or are due to impurities. Third, the absolute value of the volume extinction coefficient is small, approximately $0.5-1.5 \times 10^{-5}$ at the tropopause, indicating a haze instead of a dense cloud.

An analysis of the near infrared and polarization data has led to a volume scattering coefficient in the visible of approximately $5.5 \times 10^{-5} \mathrm{~cm}^{-1}$, and a number density of approximately 900 particles $\mathrm{cm}^{-3}$ both values being referred to the tropopause $(\mathrm{R}=6110 \mathrm{~km})$. The visible-to-infrared extinction crosssection ratio is about 5 to 10 , a quite reasonable result for micron-size 
particles, although uncertainties in refractive index tend to weaken the implied internal consistency. Carrying the chain of reasoning one step further has suggested a mass mixing ratio for the cloud material of approximately $5 \times 10^{-6}$, with consider able uncertainty. In any event the vapor mixing ratio, which is the spectroscopically important one, should be considerably less than this amount.

Finally, the theoretical extinction coefficients of sulfuric acid clouds have been compared with the measured Venus values, and the similarity is striking, though not perfect. It has been demonstrated that effects of the lunar emissivity in the reference spectrum and multiple scattering in the Venus clouds do not appear to affect any basic conclusions, although in the latter instance substances with considerably different refractive indices than those of sulfuric acid solutions (especially the imaginary parts) should be examined independently. 


\begin{abstract}
APPENDIX
The Volume Extinction Coefficient from the Mariner 10

Infrared Radiometer Investigation
\end{abstract}

The purpose of this Appendix is to derive a simple relation for the volume extinction coefficient, $\mathrm{N}_{\mathrm{p}} \chi_{\mathrm{E}}$, consistent with a linear limb darkening law and homogeneous atmosphere. The data used for numerical evaluation will be based on the Mariner 10 infrared radiometry investigation. The spectral response of the radiometer covers approximately the wavelength region from 35 to $55 \mu \mathrm{m}$ (Chase, et al., 1974). According to Chase, et al., a good fit to the $45 \mu \mathrm{m}$ $220 \mathrm{~cm}^{-1}$ ) data can be made with the expression

$$
\mathrm{I}(0, \mu)=\mathrm{I}(0,1)[0.76+0.24 \mu] \text {. }
$$

As the authors state this implies a Planck function of the form

$$
B(\tau)=B(1)[0.76+0.24 \tau]
$$

where, again according to the authors, $\mathrm{T}(\tau=1)=255 \mathrm{~K}$. Then, using a lapse rate $\gamma=9 \mathrm{~K} \mathrm{~km}^{-1}$, Chase, et al. obtained a volume extinction coefficient $\left(\mathrm{N}_{\mathrm{p}} \chi_{\mathrm{E}}\right)_{\tau=0}=0.24 \times 10^{-5} \mathrm{~cm}^{-1}$ where the derived temperature at $\tau=0$ is $\mathrm{T}=222 \mathrm{~K}$.

The above analysis, though internally consistent, is not consistent with a homogeneous atmosphere having a constant lapse rate $\gamma$. It can be shown with the aid of the perfect gas law and the equation of hydrostatic equilibrium, that 
such an atmosphere requires an extinction coefficient of the form

$$
\mathrm{N}_{\mathrm{p}} \chi_{\mathrm{E}}=\left(\mathrm{N}_{\mathrm{p}} \chi_{\mathrm{E}}\right)_{\mathrm{c}}\left(\frac{\mathrm{T}}{\mathrm{T}_{\mathrm{c}}}\right)^{\frac{\mathrm{g}}{R y}-1}
$$

where the subscript " $c$ ". indicates the cloud top (it is assumed that $\mathrm{CO}_{2}$ does not absorb appreciably in the $35-55 \mu \mathrm{m}$ range). The other parameters in eq. (A3) include the acceleration due to gravity $\mathrm{g}$ and the $\mathrm{CO}_{2}$ gas corstant $\mathrm{R}$. From eq. (5) of the text and the boundary condition $\tau \rightarrow 0$ as $z \rightarrow z_{c}$, the optical depth can then be shown to be

$$
\tau(\mathrm{T})=\left(\mathrm{N}_{\mathrm{p}} \chi_{\mathrm{E}}\right)_{\mathrm{c}} \frac{\mathrm{RT}}{\mathrm{g}}\left[\left(\frac{\mathrm{T}}{\mathrm{T}}\right)^{\frac{\mathrm{g}}{\mathrm{R} \gamma}}-1\right]
$$

It has been demonstrated empirically (Samuelson, 1969) that expression (A4) is compatible with linear limb darkening for $\mu \gtrsim 0.4$, but begins to deviate from linearity as $\mu$ becomes smaller, failing badly at $\mu=0$. Because the analysis of Chase et al. depends critically on conditions at $\tau$ and $\mu$ equal zero it is necessary to make an analysis more consistent with the homogeneous model.

The value $T(\tau=1)=255 \mathrm{~K}$ is retained, and also eqs. (A1)-(A2) where they are basically valid, that is, where both $\mu$ and $\tau$ are greater than 0.4 . Upon solving eq. (A4) for $\mathrm{T}_{c}$, one obtains 


$$
\mathrm{T}_{\mathrm{c}}=\mathrm{T}_{1}\left[\frac{1-\frac{\tau_{1}}{\tau_{2}}\left(\frac{\mathrm{T}_{2}}{\mathrm{~T}_{1}}\right)^{\frac{\mathrm{g}}{\mathrm{R} \gamma}}}{1-\frac{\tau_{1}}{\tau_{2}}}\right]^{\frac{\gamma \mathrm{R}}{\mathrm{g}}},
$$

where the subscripts 1 and 2 refer to two arbitrary levels in the atmosphere. Choosing $\tau_{1}=0.5$ and $\tau_{2}=1.0$, values for which eq. (A2) should be valid, one finds from (A2) and a table of Planck functions, that $\mathrm{T}_{1}=237 \mathrm{~K}$ and $\mathrm{T}_{2}=255 \mathrm{~K}$. Then, with $\mathrm{R}=2 \times 10^{6} \mathrm{~cm}^{2} \mathrm{sec}^{-2} \mathrm{~K}^{-1}, \mathrm{~g}=870 \mathrm{~cm} \mathrm{sec}^{-2}$, and $\gamma=5 \mathrm{~K} \mathrm{~km}^{-1}$, which is very close to the average lapse rate at the levels of interest according to the Mariner 10 radio science investigation (Howard, et al., 1974; cf. Fig. 5 this paper), one obtains $T_{c}=188 \mathrm{~K}$. Setting $\tau=1$ in (A4) then yields $\left(\mathrm{N}_{\mathrm{p}} \chi_{\mathrm{E}}\right)_{\mathrm{c}}=1.6 \times 10^{-7} \mathrm{~cm}^{-1}$. Returning to (A3) one finds a tropopause volume extinction coefficient, for $\mathrm{T}_{0}=273 \mathrm{~K}$, of $\left(\mathrm{N}_{\mathrm{p}} \chi_{\mathrm{e}}\right)_{0}=3 \times 10^{-6} \mathrm{~cm}^{-1}$, which is eq. (13) of the text. Also, as stated in the text, the lapse rate $\gamma=9 \mathrm{~K} \mathrm{~km}^{-1}$ suggested by Chase, et al. yields $\left(\mathrm{N}_{\mathrm{p}} \chi_{\mathrm{E}}\right)_{0}=5 \times 10^{-6} \mathrm{~cm}^{-1}$. Finally, a lapse rate of less than about $\gamma=4.6 \mathrm{~K} \mathrm{~km}^{-1}$ will not admit a solution for $\mathrm{T}_{\mathrm{c}}$ from eq. (A5), because the quantity in brackets becomes negative. 


\section{REFERENCES}

Belton, M. J. S. (1968). Theory of the Curve of Growth and Phase Effects in a Cloudy Atmosphere: Applications to Venus. J. Atmos. Sci. 25, 596-609. , Hunten, D. M., and Goody, R. M. (1968). "The Atmospheres of Venus and Mars," pp. 69-98. Gordon and Breach, New York.

Chase, S. C., Miner, E. D., Morrison, D., Münch, G., and Neugebauer, G. (1974). Preliminary Infrared Radiometry of Venus from Mariner 10. Science 183, 1291-1292.

Coffeen, D. L., and Gehrels, T. (1969). Wavelength Dependence of Polarization. XV. Observations of Venus. Astron. J. $\underline{74}, 433-445$.

Fjeldbo, G., Kliore, A., and Eshleman, V. R. (1971). The Neutral Atmosphere of Venus as Studied with the Mariner 5 Radio Occultation Experiment. Astron. J. 76, 123-140.

Gierasch, P., and Goody, R. (1970). Models of the Venus Clouds. J. Atmos. Sci. $\underline{27}, 224-245$.

Gillet, F. C., Low, F. J., and Stein, W. A. (1968). Absolute Spectrum of Venus from 2.8 to 14 Microns. J. Atmos. Sci. 25, 594-595.

Hanel, R., Foreman, M., Stambach, G., and Meilleur, T. (1968). Preliminary Results of Venus Observations Between 8 and 13 Microns. J. Atmos. Sci. $\underline{25}, 586-593$. 
Meilleur, T., Westcott, R., and Pritchard, J. (1969).

A Double Beam Interferometer for the Middle Infrared. App. Opt. 8, 20592065.

, Kunde, V. G., Meilleur, T., and Stambach, G. (1971). High Spectral Resolution in Interferometric Planetary Observations in the 7-25 $\mu$ Region. In "Planetary Atmospheres" (IAU Symposium No. 40) (C. Sagan, T. C. Owen, and H. J. Smith, eds.), pp. 44-47. Springer-Verlag, New York.

Hansen, J. E. (1969). Absorption-Line Formation in a Scattering Planetary Atmosphere: a Test of van de Hulsts Similarity Relations. Astrophys. J. $\underline{158}, 337-349$. , and Arking, A. (1971). Clouds of Venus: Evidence for Their Nature. Science 171, 669-672. , and Hovenier, J. W. (1974). Interpretation of the Polarization of

Venus. J.Atmos. Sci. 31, 1137-1160.

Howard, H. T., Tyler, G. L., Fjeldbo, G., Kliore, A. J., Levy, G. S., Brunn, D. L., Dickinson, R., Edelson, R. E., Martin, W. L., Postal, R. B., Seidel, B., Sesplaukis, T. T., Shirley, D. L., Stelzried, C. T., Sweetnam, D. N., Zygielbaum, A. I., Esposito, P. B., Anderson, J. D., Shapiro, I. I., and Reasenberg, R. D. (1974). Venus: Mass, Gravity Field, Atmosphere, and Ionosphere as Measured by the Mariner 10 Dual-Frequency Radio System. $\underline{\text { Science }} \underline{183}, 1297-1301$. 
Kunde, V. G., and Maguire, W. C. (1974). Direct Integration Transmittance Model. J. Quant. Spect. Rad. Trans. (accepted for publication).

Logan, L. M., Hunt, G. R., Balsamo, S. R., and Salisbury, J. W. (1972). Midinfrared Emission Spectra of Apollo 14 and 15 Soils and Remote Compositional Mapping of the Moon. Geochim. et Cosmochim. Acta 3 , 3069-3076.

Low, F. J. (1966). Observations of Venus, Jupiter, and Saturn at $\lambda 20$ Microns. Astron. J. 71, 6 .

Montgomery, C. G., Saari, J. M., Shorthill, R. W., and Six, N. F. Jr. (1966). "Directional Characteristics of Lunar Thermal Emission." Brown Engin. Co., Inc. Res. Lab. TN R-213 (Boeing Sci. Res. Lab. Doc. D1-82-0568).

Murcray, F. H., Murcray, D. G., and Williams, W. J. (1970), Infrared Emissivity of Lunar Surface Features, I. Balloon-Borne Observations. J. Geophys. Res. $\underline{75}, 2662-2669$.

Murray, B. C., Wildey, R. L., and Westphal, J. A. (1963). Infrared Photometric Mapping of Venus through the 8- to 14-Micron Atmospheric Window J. Geophys. Res. $68,4813-4818$. , Belton, M. J. S., Danielson, G. E., Davies, M. E., Gault, D., Hapke, B., O'Leary, B., Strom, R. G., Suomi, V., Trask, N. (1974). Venus: Atmospheric Motion and Structure from Mariner 10 Pictures. Science 183, $1307-1315$. 
Pettit, E. (1961). "The Solar System, Vol. III, Planets and Satellites," Chapt. 10. U. of Chicago Press.

Potter, J. F. (1969). Effect of Cloud Scattering on Line Formation in the Atmosphere of Venus. J. Atmos. Sci. 26, 511-517.

Remsberg, E. E. (1973). Stratospheric Aerosol Properties and Their Effects on Infrared Radiation. J. Geophys. Res. 78, 1401-1408.

Samuelson, R. E. (1968). The Particulate Medium in the Atmosphere of Venus. J. Atmos. Sci. 25, 634-643. , (1969). The Thermal Radiation Field Emitted by Anisotropically Scattering Cloudy Planetary Atmospheres. Icarus 10, 258-273.

Sill, G. T. (1972). Sulfuric Acid in the Clouds of Venus. Comm. Lunar Plan. Lab. 9, No. $171,191-198$.

Sinton, W. M. (1963). Infrared Observations of Venus. Mem. Soc. Roy. Sci., Leige $7,300-310$. , and Strong, J. (1960). Radiometric Observations of Venus. Astrophy. J. 131, 470-490.

Vinogradov, A. P., Surkov, Yu. A., and Florensky, C. P. (1968). The Chemical Composition of the Venus Atmosphere Based on the Data of the Interplanetary Station Venera 4. J. Atmos. Sci. 25, 535-536. 
Westphal, J. A. (1966). The 10-Micron Limb Darkening of Venus. J. Geophys. Res. 71, 2693-2696.

, Wildey, R. L., and Murray, B. C. (1965). The 8-14-Micron

Appearance of Venus Before the 1964 Conjunction. Astrophys. J. 142, 799-802.

Young, A. T. (1973). Are the Clouds of Venus Sulfuric Acid? Icarus 18, $564-582$.

(1974). Venus Clouds: Structure and Composition. Science 183, 407-409.

Young, L. D. Gray, and Young, A. T. (1973). Comment on "The Composition of the Venus Cloud Tops in Light of Recent Spectroscopic Data." Astrophys. J. $179, \mathrm{~L} 39-\mathrm{I} 43$. 


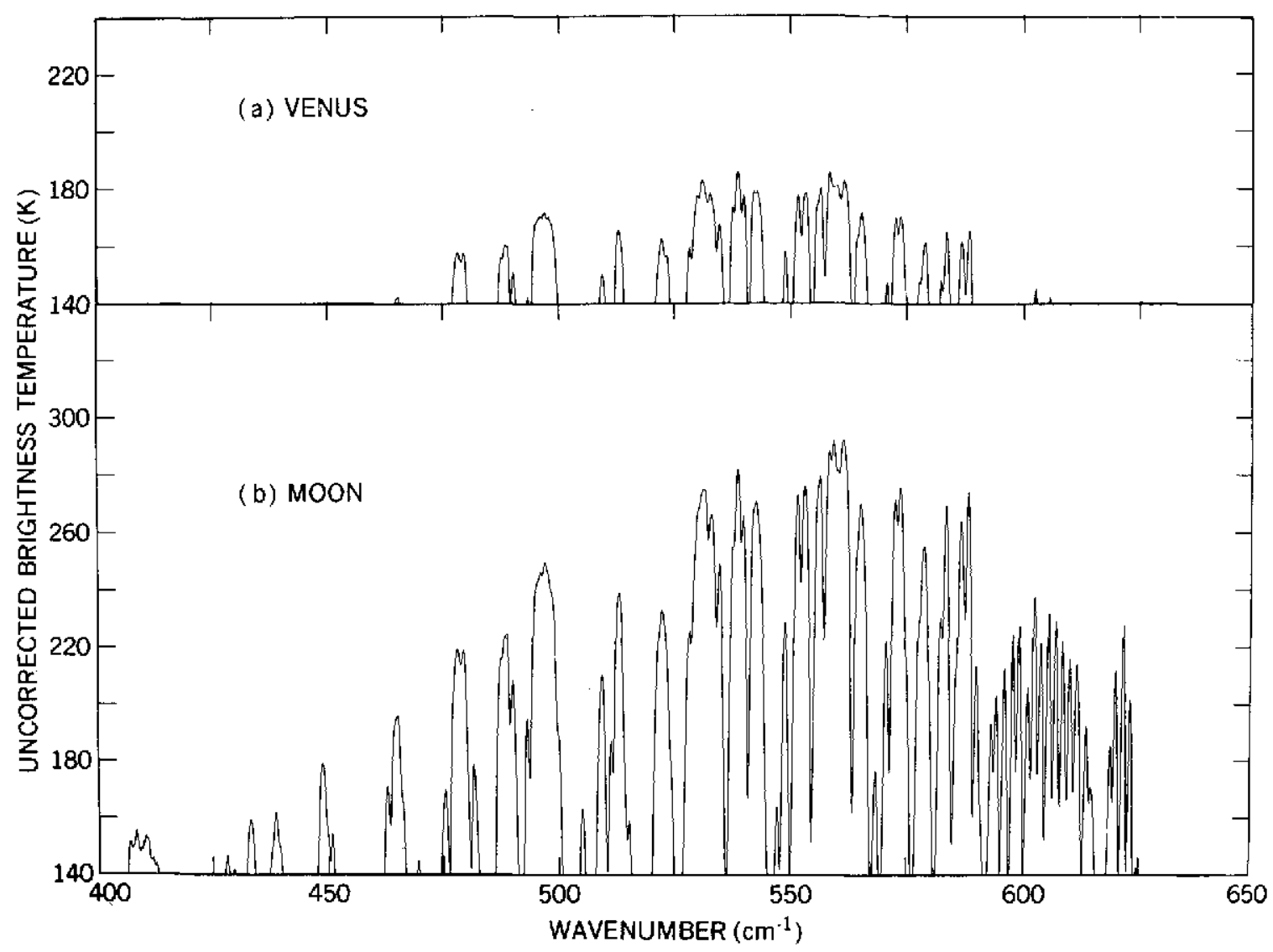

Figure 1. (a) Venus and (b) lunar uncorrected brightness temperature spectra over the wavenumber range $400-650 \mathrm{~cm}^{-1}$. Atmospheric and telescope transmission characteristics still remain in the spectra. The uncor rected temperatures can be converted to actual brightness temperatures by dividing by the fourth root of the product of atmospheric and telescope transmission functions. 


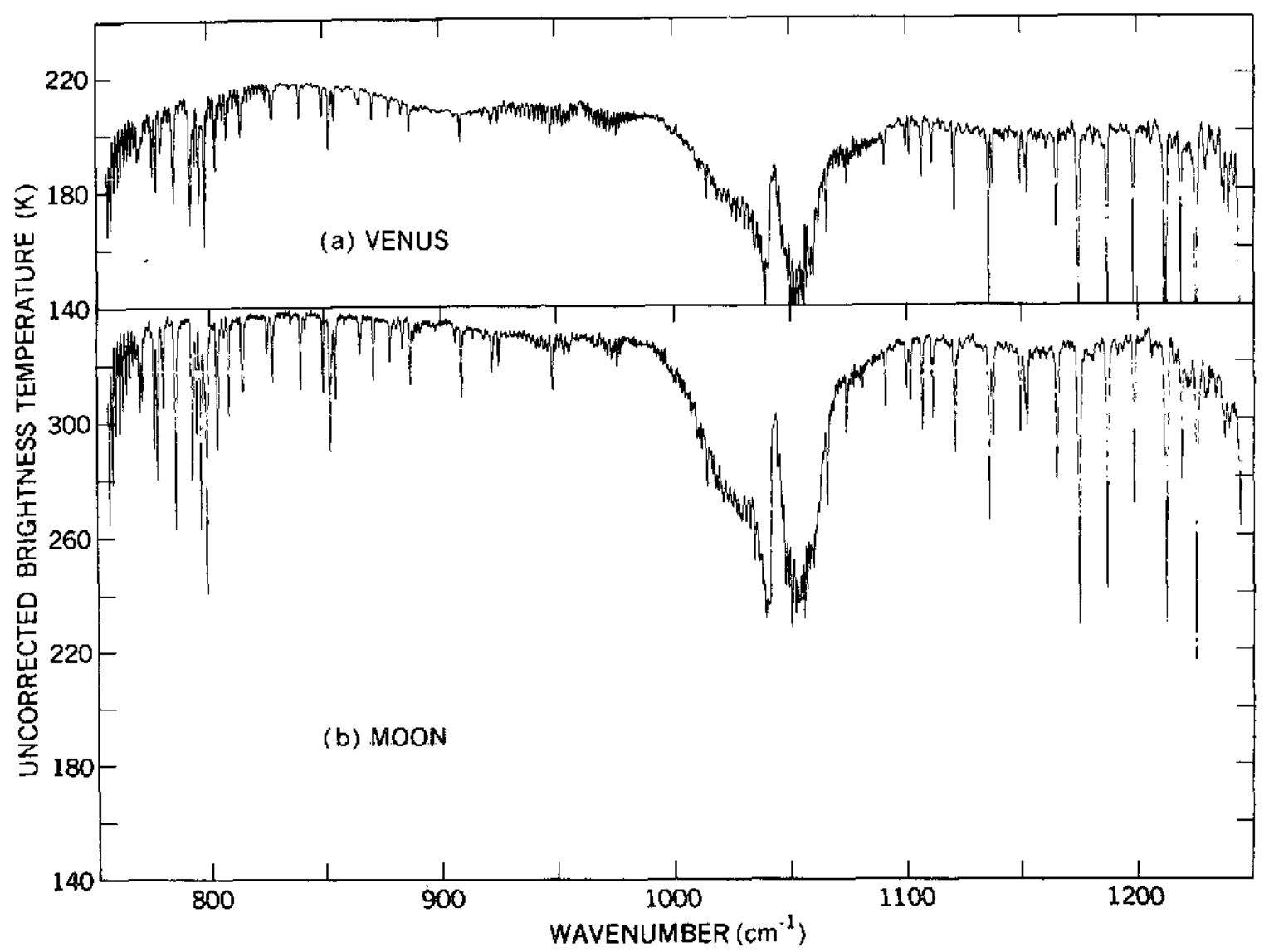

Figure 2. (a) Venus and (b) lunar uncor rected brightness temperature spectra over the wavenumber range $750-1250 \mathrm{~cm}^{-1}$. Atmospheric and telescope transmission characteristics still remain in the spectra. The uncorrected temperatures can be converted to actual brightness temperatures by dividing by the fourth root of the product of atmospheric and telescope transmission functions. 

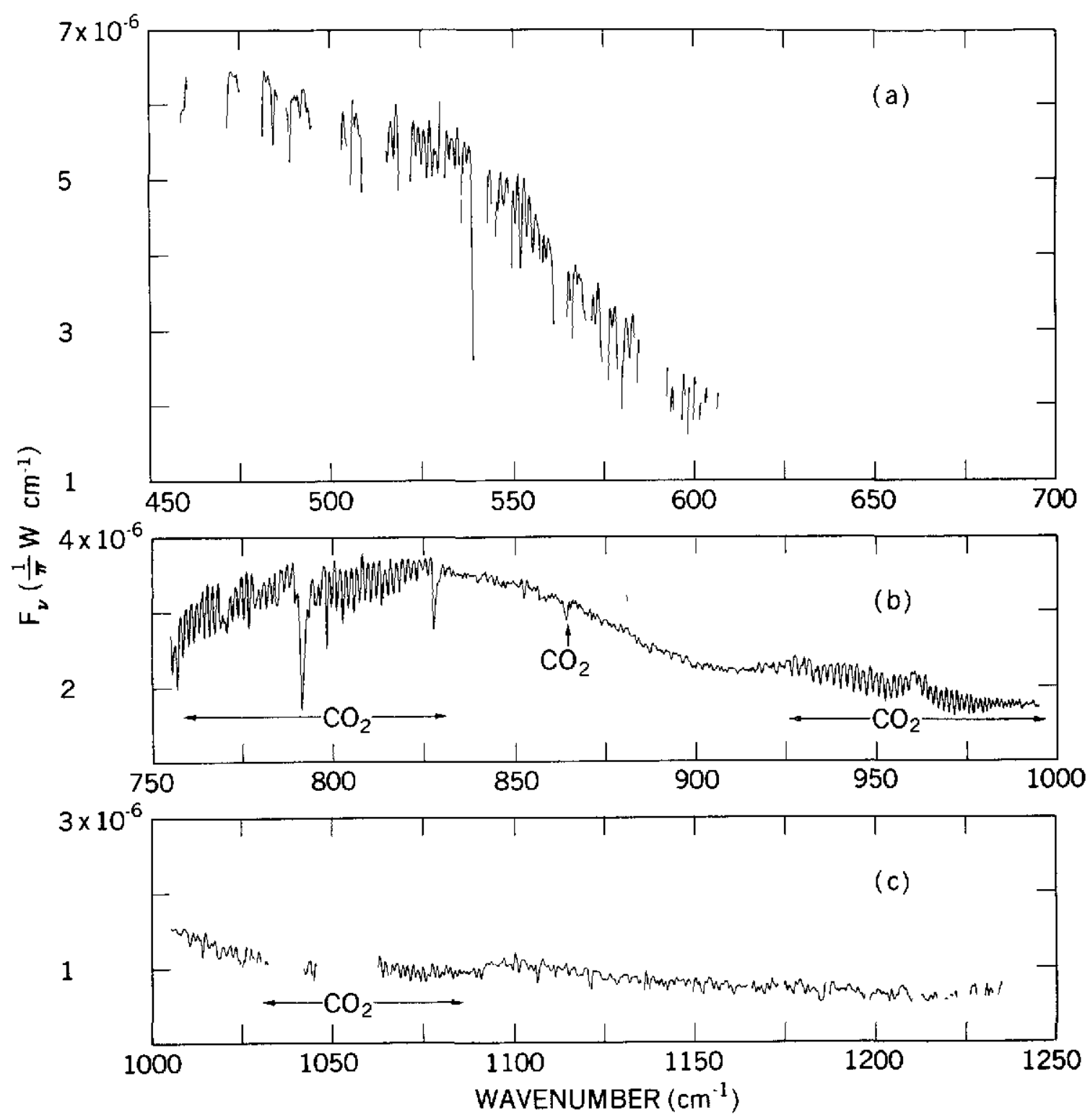

Figure 3. Venus/lunar ratio spectrum, defined by eq. (3), over the wavenumber intervals (a) $450-700^{-1}$, (b) $750-1000 \mathrm{~cm}^{-1}$, and (c) $1000-$ $1250 \mathrm{~cm}^{-1}$. 


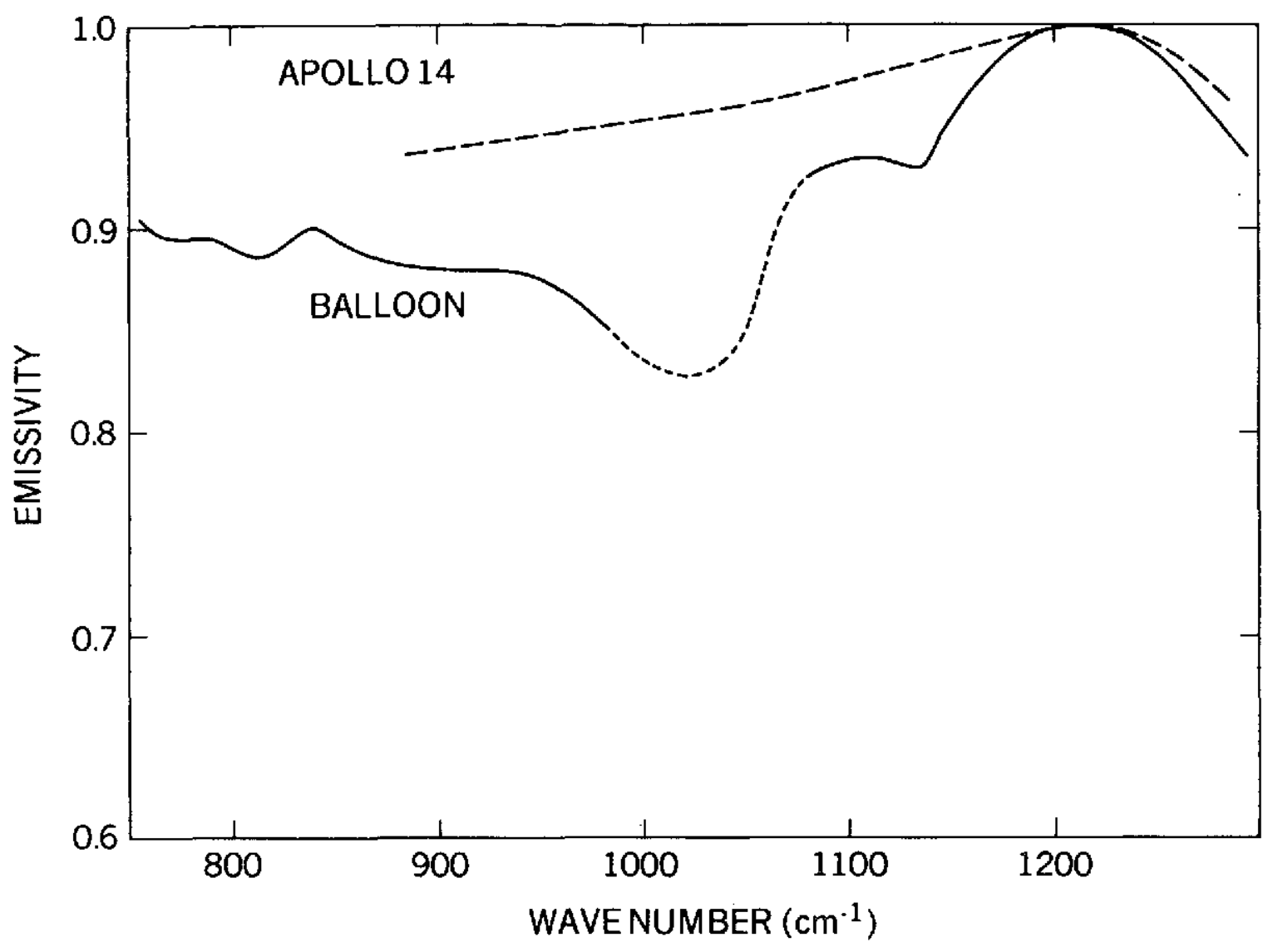

Figure 4. Lunar emissivity according to balloon spectroscopy (Murcray, et al., 1970) and laboratory measurements of Apollo 14 lunar soil samples (Logan, et al., 1972). 


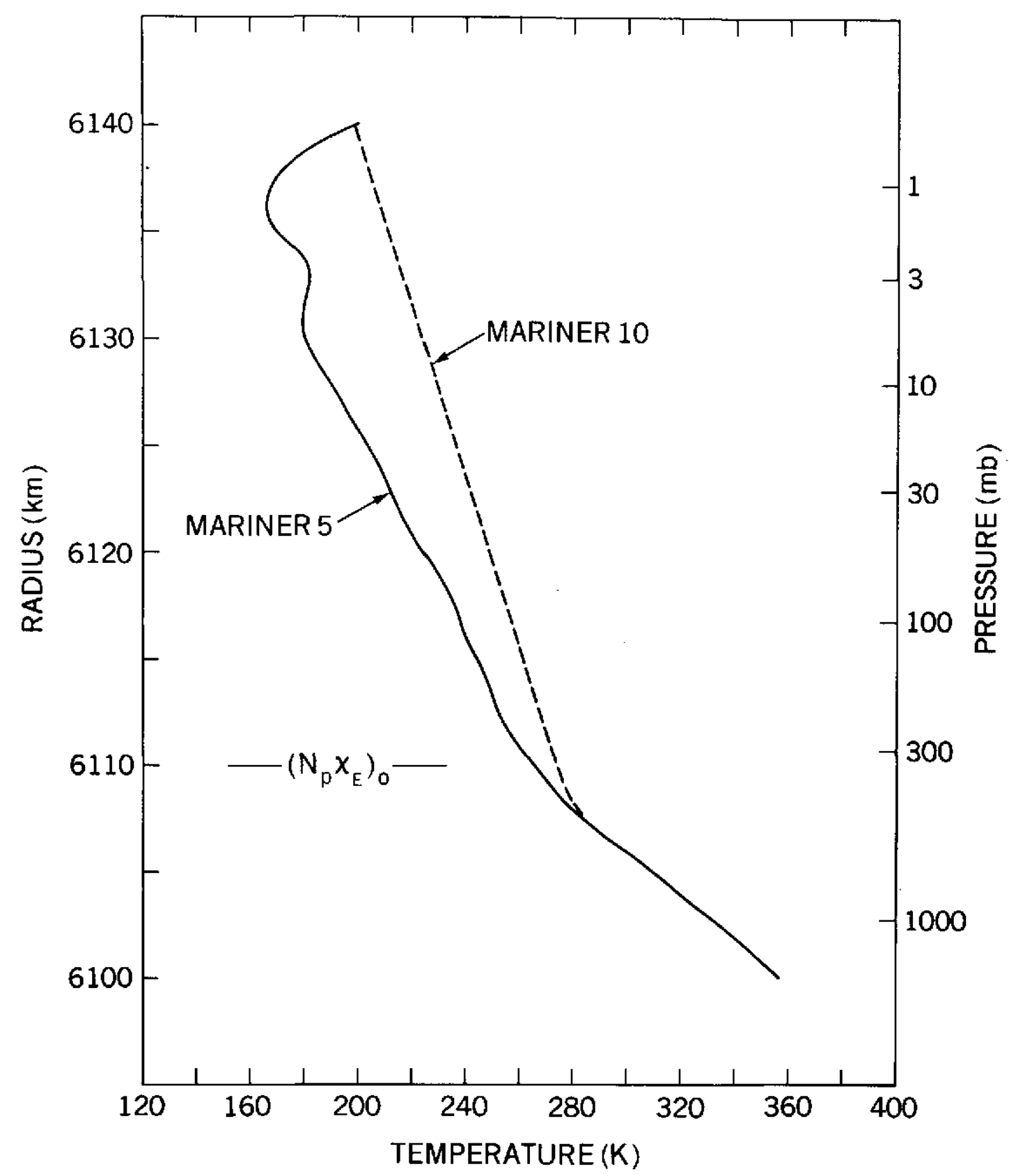

Figure 5. Venus temperature profiles according to Mariner S-band investigations. The Mariner 5 profile is a slightly smoothed average of profiles derived from both ingression and egression data, and is the profile used for quantitative model calculations. The Mariner 10 profile is a straight line approximation of ingression data. $R=6110 \mathrm{~km}$ is the level to which all opacity calculations will be referred. 


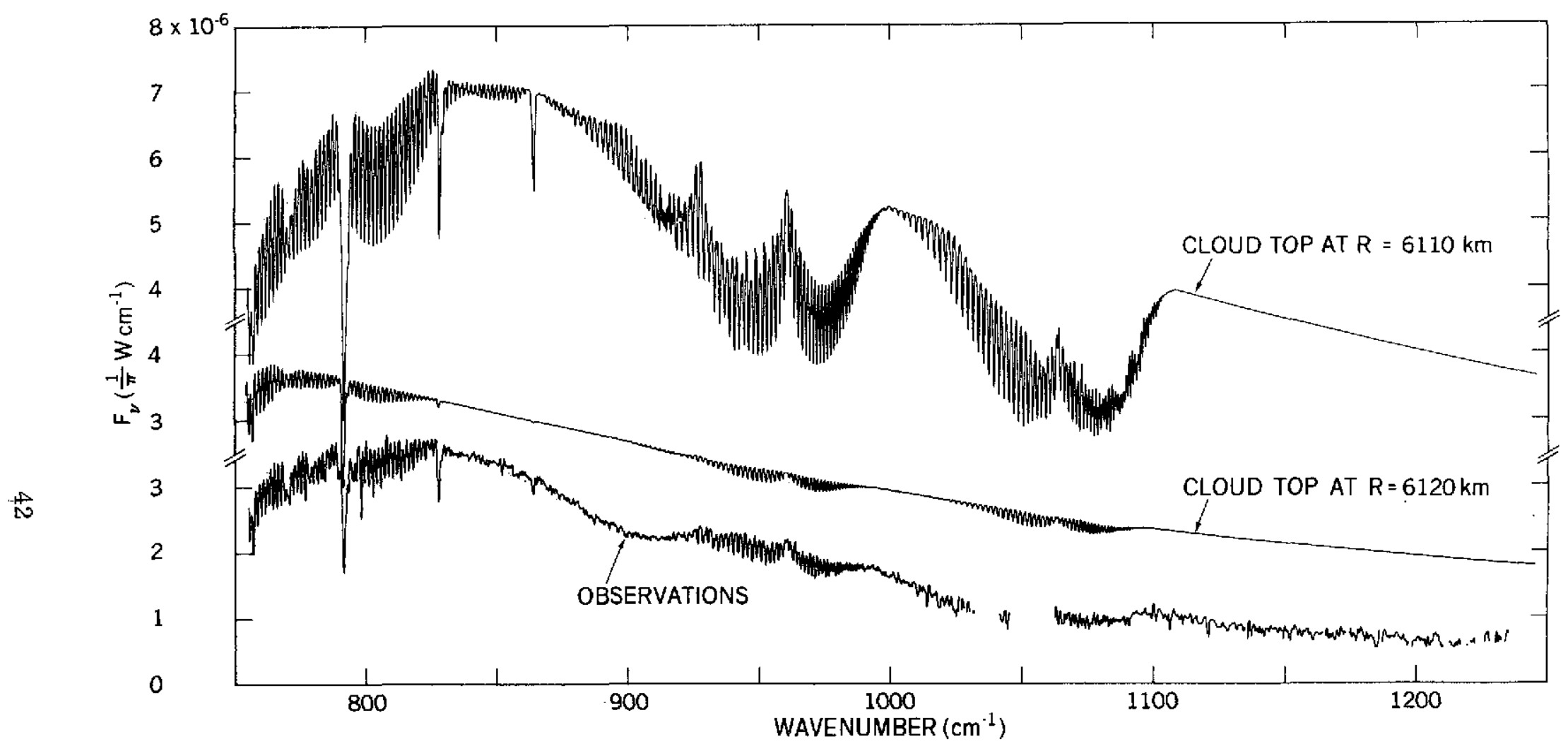

Figure 6. Observed Venus/lunar ratio spectrum defined by eq. (3), and two synthetic spectra, considering $\mathrm{CO}_{2}$ as the sole opacity source. Blackbody clouds having tops at $\mathrm{R}=6120$ and $6110 \mathrm{~km}$ form the lower boundaries, and the Mariner 5 data (Fig. 5) provide the temperature profile of the model atmospheres from which the synthetic spectra are computed. There is a displacement of the outer curves relative to the middle curve of one vertical subdivision to enhance readability. The spectral range is $750-1250 \mathrm{~cm}^{-1}$. 


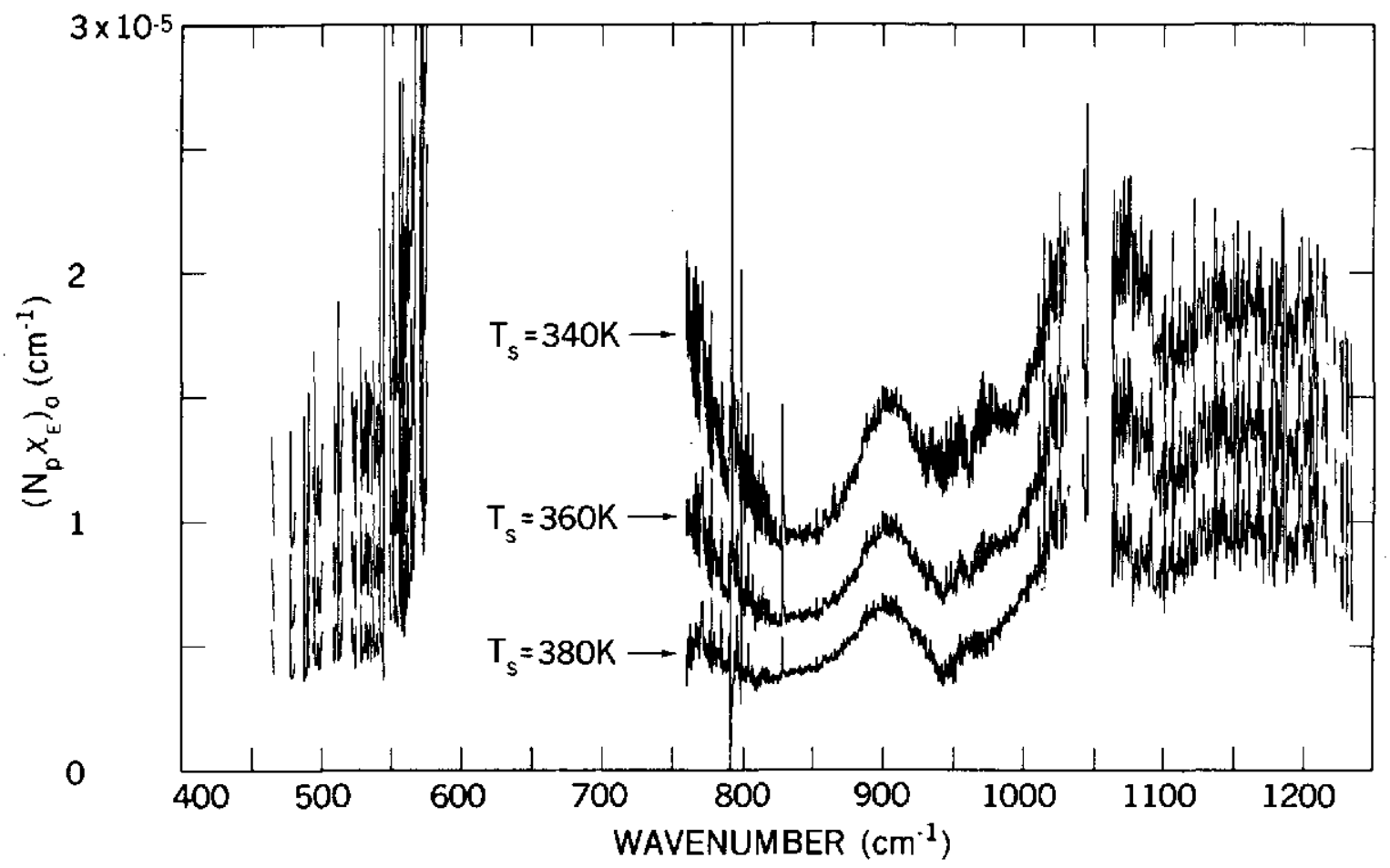

Figure 7. Observed volume extinction coefficient referred to the $R=6110 \mathrm{~km}$ level. Three lunar surface temperatures are assumed, with $\mathrm{T}_{\mathrm{s}}=360 \mathrm{~K}$ considered the most probable. Unit lunar emissivity is assumed for all three curves. 


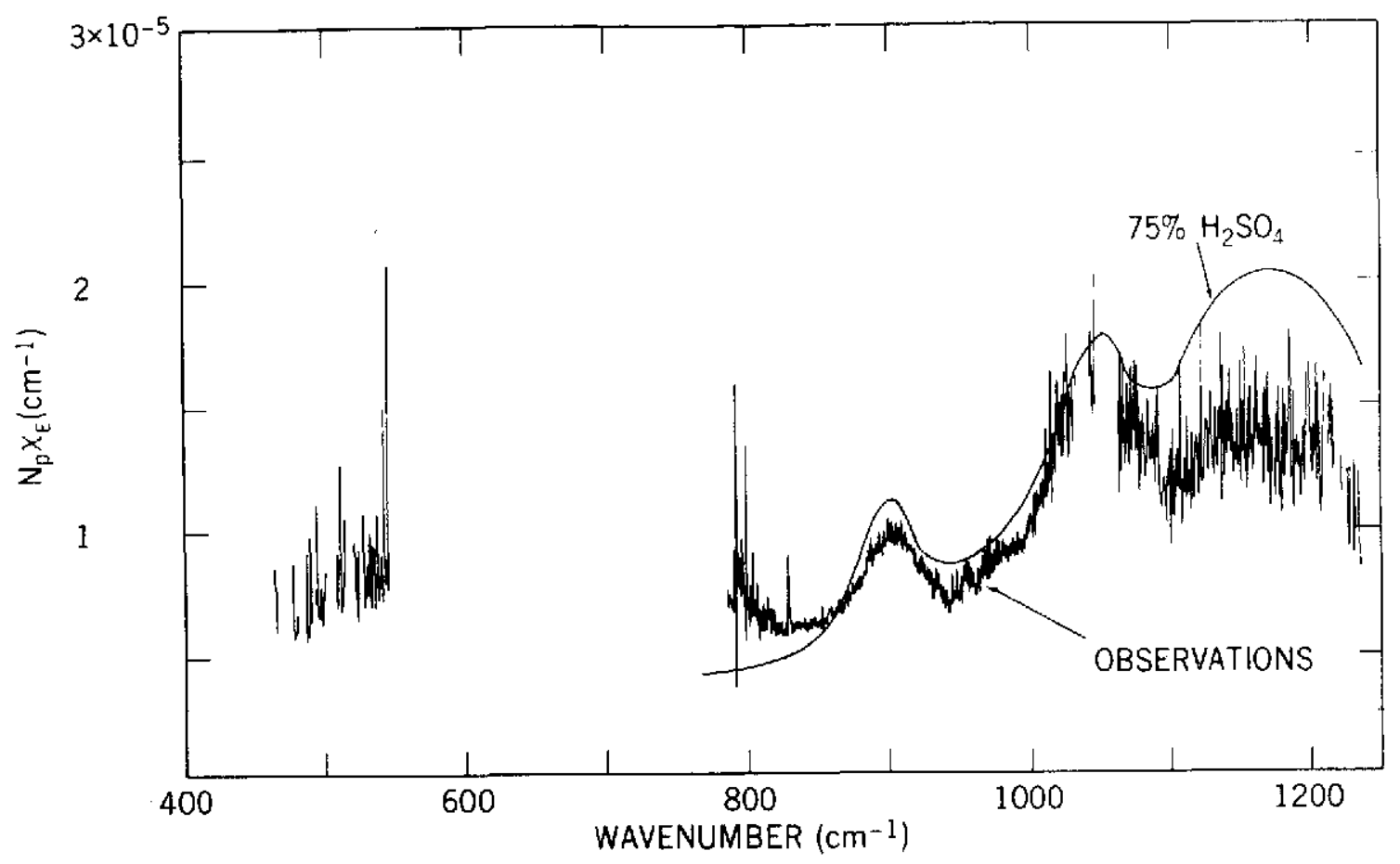

Figure 8. The middle curve of Fig. $7\left(\mathrm{~T}_{\mathrm{s}}=360 \mathrm{~K}\right)$ is compared with the volume extinction coefficient calculated for the sulfuric acid cloud model described in the text. The values for the sulfuric acid cloud have been scaled down to two-thirds $(0.67)$ their actual value for the purpose of comparison. 


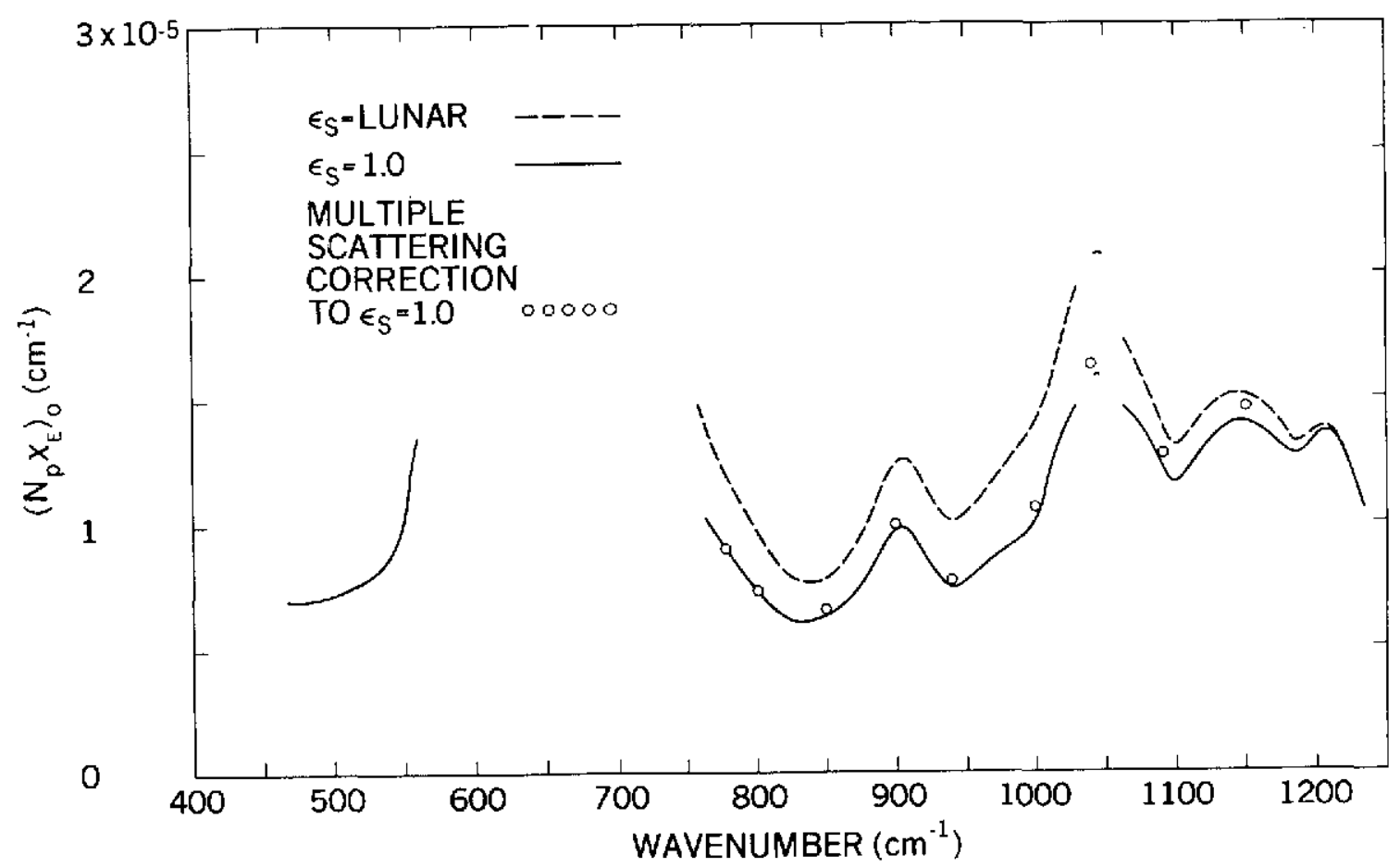

Figure 9. Smoothed freehand versions of the volume extinction coefficient for a lunar surface temperature of $\mathrm{T}_{\mathrm{s}}=360 \mathrm{~K}$. Unit emissivity is assumed for the solid curve, while the lunar emissivity given by the balloon data, Fig. 4, is assumed for the dashed curve. The open circles show the multiple scattering corrections to the solid curve at selected wavenumbers. 